Original Article

\title{
Respiratory Function of University Students Living at High Altitude
}

\author{
Hyolyun Roh, PhD, $\mathrm{PT}^{1)^{*}}$, Daehee Lee, PhD, $\mathrm{PT}^{2)}$ \\ 1) Department of Occupational Therapy, Kangwon National University: 3 Hwangio-ri, Samcheok-si, \\ Gangwon-do 240-907, Republic of Korea \\ 2) Department of Physical Therapy, Youngdong University, Republic of Korea
}

\begin{abstract}
Purpose] This study compared the respiratory function and oxygen saturation levels of university students living at high altitude, to present a new approach for improving respiratory function using high altitudes above sea level. [Subjects and Methods] The subjects were 100 female students attending a university located approximately $850 \mathrm{~m}$ above sea level and 104 female students attending a university located at low altitude. Oxygen saturation, heart rate (HR), and respiratory function levels were measured. [Results] For the students living at high altitude, HR, PEF, and FEV1/FVC levels were low. In contrast, their oxygen saturation, FEV1, and FVC levels were higher than the levels found in students living at low altitude. Differences in respiratory function were revealed in first- and second-year students living at high and low altitudes. On the other hand, no significant differences in respiratory function were found between third- and fourth-year students. [Conclusion] University students living at high altitude had a slower HR and higher oxygen saturation levels as well as higher lung and inspiratory capacity levels. Thus, physiological improvement in oxygen saturation levels and pulmonary function were seen in the individuals living at high altitude.

Key words: High-altitude, Respiratory function, Vital capacity
\end{abstract}

(This article was submitted Feb. 14, 2014 and was accepted Mar. 31, 2014)

\section{INTRODUCTION}

Although it is difficult to define a high altitude, it is generally accepted as being over $3,000 \mathrm{~m}$ above sea level where clinical, physiological, anatomical, and biochemical changes can be substantial ${ }^{1)}$. At high altitude, the human body experiences various physiological responses, such as an increase in breathing capacity, an increase in cardiac output during submaximal exercises, and an increase in maximum aerobic power ${ }^{2}$. In addition, it is well known that decreases in atmospheric pressure at high altitude result in pulmonary function efficiently carrying oxygen due to a decrease in the partial pressure of oxygen in alveolar and arterial blood ${ }^{3)}$. These characteristics of high altitude can be utilized to strengthen physiological function in relation to pulmonary function $^{4)}$. To breathe, oxygen is inhaled and transferred to the bloodstream and carbon dioxide is expelled by exhalation after the oxygen has been used by the body. Therefore, respiratory function is a very important function for humans. Although Korea has many mountains, the number of mountains exceeding $1,500 \mathrm{~m}$ is relatively few so hardly any Koreans live at high altitude. Due to this environment

*Corresponding author. Hyolyun Roh (E-mail: withtry@ kangwon.ac.kr)

(C) The Society of Physical Therapy Science. Published by IPEC Inc.

This is an open-access article distributed under the terms of the Creative Commons Attribution Non-Commercial No Derivatives (by-ncnd) License $<$ http://creativecommons.org/licenses/by-nc-nd/3.0/>. in Korea, many athletes spend much money to participate in high-altitude training overseas. Despite equivocal findings about the benefits at high-altitude training, current theory dictates that the best approach is to spend several weeks living at 2,500 $\mathrm{m}$ and train near sea level ${ }^{5}$. For these reasons, various methods have recently been attempted to gain the advantages of high altitude while overcoming its disadvantages. For example, a training program called living hightraining low (LHTL) uses low-oxygen tents, intermittent exposure to low oxygen, and low-oxygen sleep to gain the advantages of high-altitude training ${ }^{6}$. In addition, recent studies have reported that improvement in pulmonary function can be achieved by living alternately at $850 \mathrm{~m}$ above sea level, and at low altitude. Daily living at high altitude can improve the pulmonary function while alternate daily living between high-altitude and low-altitude places can elicit similar effects ${ }^{7}$. According to Roh's study ${ }^{7)}$, which argues that pulmonary function can be improved by alternate high and low-altitude living, it is appropriate to find a method for strengthening pulmonary function using the environment at high-altitude location. If daily living at high altitude could improve the pulmonary function, the high costs of training overseas could be reduced, and a new method for improving the skills of athletes whose pulmonary function is important to their athletic performance could be established. In addition, not only athletes but also the public would benefit from advancements in methods for improving pulmonary function or respiratory-related difficulties through environmental conditions.

Accordingly, the present study conducted a comparison 
of respiratory function and oxygen saturation levels between female students living at high altitude and low altitudes.

\section{SUBJECTS AND METHODS}

The present study investigated the differences in pulmonary function of university students living at high and low altitudes. To achieve this objective, the pulmonary function of female university students attending K University, located approximately $850 \mathrm{~m}$ above sea level, and Y University, located at low altitude, were determined. The study's objective and procedure were explained to the study subjects and their consent to participation was obtained. The ethical committee of Kangwon National University Hospital's institutional review board approved the study. K University is located in Gangwon-do where mountainous terrain is common. Students of K University, which is located $850 \mathrm{~m}$ above sea level, take classes for approximately 20 hours every week for 15 weeks in a single semester, commuting to and from a dormitory located at $200 \mathrm{~m}$ above sea level. During school holidays, they return to their homes located in metropolitan cities, which are at low altitudes. Thus, $\mathrm{K}$ University students experience daily living at both high and low altitudes. On the other hand, Y University is located in Chungbuk Province where plains are common. Y University and its dormitory are both located at a low altitude. In this study, students of K University are henceforth referred to as high altitude living students while students of Y University are referred to as low-altitude living students. The oxygen saturation levels, HR, and pulmonary function of the female students of $\mathrm{K}$ and $\mathrm{Y}$ Universities were measured at a dormitory located at a low altitude at the same time between $5 \mathrm{pm}$ and $6 \mathrm{pm}$. The experiment was conducted on October 2-25, 2013. In order to eliminate measurement errors between the two universities, we had two measurers from both universities to ensure the same measurement method was used. After training, three measurers performed the test measurements and the intra-class correlation coefficient of inter-tester reliability was found to be 0.93 .

The study subjects were chosen based on a history of no respiratory-related diseases, autonomic nervous system disability or symptoms, as well as no smoking history. In addition, for the two months prior to the measurements, they did not exercise for more than 20 minutes a day, which can affect cardiovascular function. The subjects attending $\mathrm{K}$ University included 25 first-year students (average age: $18.92 \pm 0.57$ years, average height: $163.04 \pm 4.25 \mathrm{~cm}), 25$ second-year students (average age: $19.96 \pm 0.54$ years, average height: $161.52 \pm 5.45 \mathrm{~cm}$ ), 25 third-year students (average age: $21.04 \pm 0.35$ years, average height: $159.84 \pm 4.40 \mathrm{~cm}$ ), and 25 fourth-year students (average age: $22.12 \pm 0.67$ years, average height: $160.80 \pm 4.17 \mathrm{~cm}$ ) totaling 100 students. The average age and height of the study subjects from K University were 20.51 years and $161.30 \mathrm{~cm}$. Subjects attending Y University included 28 first-year students (average age: $18.14 \pm 0.36$ years, average height: $161.86 \pm 5.27 \mathrm{~cm}$ ), $25 \mathrm{sec}-$ ond-year students (average age: $19.12 \pm 0.44$ years, average height: $162.56 \pm 4.27 \mathrm{~cm}$ ), 25 third-year students (average age: $20.04 \pm 0.46$ years, average height: $159.88 \pm 5.04 \mathrm{~cm}$ ), and 26 fourth-year students (average age: $21.12 \pm 0.59$ years, average height: $162.00 \pm 5.08 \mathrm{~cm}$ ) a total of 104 students. The average age and height of the study subjects from Y University were 20.66 years and $161.59 \mathrm{~cm}$.

Oxygen saturation and HR (beats per minute: bpm) levels were measured using an instrument that calculates heart rate and arterial blood oxygen saturation levels (Pulse Oximeter, MP110P, Mek-ICS Co., Korea). The pulse oximeter was attached to the subject's middle fingers and the levels were measured in a stable state 68 times within five minutes. Then, the average of the measured levels was calculated. Pulse oximetry is a non-invasive method that uses an instrument to monitor oxygen saturation levels easily and quickly, and displays the measured levels as $\mathrm{SpO}_{2}$. In this study, forced vital capacity (FVC), forced expiration volume of 1 second (FEV1), peak forced expiratory flow (PEF), and forced vital capacity of 1 second were measured using cardiopulmonary measuring instruments (Microplus Spirometer, Carefusion Co., UK). The FEV1/FVC ratio was calculated. When subjects arrived at the measurement location, they were instructed to rest for more than five minutes to ensure that their condition was normal. Then, oxygen saturation and HR levels were measured using the right index finger. Demonstrations and explanations about the required posture were provided before measuring cardiopulmonary function, which was done three times. The averages of the measured levels were used in the study. Vital capacity was measured using the method recommended for chronic obstructive pulmonary disease patients by referring to the standard guidelines ${ }^{8}$ ) for the implementation and reading of pulmonary function tests published by the American Thoracic Society and the European Respiratory Society. When pulmonary function was measured, the subjects were instructed to look forward, while standing in an upright position. The subjects were instructed to maximally inhale and then exhale quickly and strongly for the longest time possible, while firmly holding the nose and properly biting the mouthpiece. To obtain better measurement results, the subjects were encouraged by a researcher saying, more, more, more, hoo. The subject was instructed to rest for approximately two minutes after each measurement so as not to record rebound measurements. When measured levels could not be properly obtained because the subject coughed or otherwise, the subject was instructed to rest, after which the measurement was repeated.

The data were analyzed using SPSS 12.0 for Windows and the paired t-test to determine respiratory function and oxygen saturation levels according to grade. The statistical significance level was chosen as $\mathrm{p}=0.05$.

\section{RESULTS}

This study was conducted to compare the cardiopulmonary functions of female university students living at high altitude and low altitudes. Oxygen saturation and cardiopulmonary function levels of the students attending the college located at low altitude and those attending the col- 
Table 1. Comparison of pulmonary functions of female university students at low and high altitude

\begin{tabular}{lcccccc}
\hline & $\begin{array}{c}\mathrm{HR}^{* *} \\
(\mathrm{bpm})\end{array}$ & $\begin{array}{c}\text { Oxygen } \\
\text { saturation** } \\
(\%)\end{array}$ & $\begin{array}{c}\mathrm{FEV}^{* *} \\
(\mathrm{ml})\end{array}$ & $\begin{array}{c}\mathrm{FVC}^{* *} \\
(\mathrm{ml})\end{array}$ & $\begin{array}{c}\mathrm{PEF}^{* *} \\
(\mathrm{ml})\end{array}$ & $\mathrm{FEV1/FV**}$ \\
\hline High altitude & $77.73 \pm 10.34$ & $98.26 \pm 1.02$ & $2.65 \pm 0.38$ & $2.87 \pm 0.46$ & $318.10 \pm 71.78$ & $0.93 \pm 0.77$ \\
Low altitude & $82.15 \pm 9.09$ & $97.68 \pm 1.50$ & $2.39 \pm 0.46$ & $2.45 \pm 0.49$ & $363.20 \pm 74.63$ & $0.98 \pm 0.04$ \\
\hline
\end{tabular}

$* * \mathrm{p}<0.01$, HR: heart rate, FEV1: forced expiratory volume of one sec, FVC: expiratory flow rate obtained by fastest expiration after maximal inhalation, PEF: peak expiratory flow, FEV1/FVC: the ratio of forced expiration volume for $1 \mathrm{sec}$ to forced vital capacity.

Table 2. Comparison of pulmonary function of female university students by grade level

\begin{tabular}{llllllll}
\hline & & \multicolumn{1}{c}{$\begin{array}{c}\text { HR } \\
(\mathrm{bpm})\end{array}$} & $\begin{array}{c}\text { Oxygen } \\
\text { saturation }(\%)\end{array}$ & $\begin{array}{c}\text { FEV1 } \\
(\mathrm{ml})\end{array}$ & $\begin{array}{c}\text { FVC } \\
(\mathrm{ml})\end{array}$ & $\begin{array}{c}\text { PEF } \\
(\mathrm{ml})\end{array}$ & $\begin{array}{c}\text { FEV1/FVC } \\
(\%)\end{array}$ \\
\hline \multirow{2}{*}{ Freshmen } & H & $78.04 \pm 10.23$ & $98.44 \pm 0.77^{* *}$ & $2.62 \pm 0.46$ & $2.96 \pm 0.47^{* *}$ & $279.84 \pm 82.26^{* *}$ & $0.88 \pm 0.02$ \\
& $\mathrm{~L}$ & $82.76 \pm 8.88$ & $97.32 \pm 1.95$ & $2.38 \pm 0.46$ & $2.41 \pm 0.47$ & $374.24 \pm 72.29$ & $0.99 \pm 0.02$ \\
Sopho- & $\mathrm{H}$ & $76.84 \pm 11.85^{*}$ & $98.32 \pm 0.80$ & $2.69 \pm 0.40^{* *}$ & $2.98 \pm 0.53^{* *}$ & $307.04 \pm 62.84^{* *}$ & $0.91 \pm 0.08^{* *}$ \\
mores & $\mathrm{L}$ & $83.64 \pm 9.56$ & $97.96 \pm 1.02$ & $2.28 \pm 0.32$ & $2.31 \pm 0.32$ & $371.81 \pm 76.02$ & $0.99 \pm 0.02$ \\
& $\mathrm{H}$ & $75.92 \pm 7.63$ & $98.32 \pm 1.18$ & $2.57 \pm 0.35$ & $2.66 \pm 0.39$ & $326.27 \pm 62.73$ & $0.97 \pm 0.54$ \\
Juniors & $\mathrm{L}$ & $78.96 \pm 9.97$ & $97.60 \pm 1.66$ & $2.45 \pm 0.35$ & $2.54 \pm 0.34$ & $325 \pm 71.77$ & $0.97 \pm 0.06$ \\
& $\mathrm{H}$ & $80.12 \pm 11.31$ & $97.96 \pm 1.24$ & $2.70 \pm 0.30$ & $2.86 \pm 0.38^{* *}$ & $356.15 \pm 57.56$ & $0.95 \pm 0.06$ \\
Seniors & $\mathrm{L}$ & $83.32 \pm 7.50$ & $97.88 \pm 1.20$ & $2.46 \pm 0.63$ & $2.53 \pm 0.71$ & $378.72 \pm 65.17$ & $0.97 \pm 0.05$ \\
\hline
\end{tabular}

$* \mathrm{p}<0.05,{ }^{*} \mathrm{p}<0.01, \mathrm{H}$ : high altitude, L: low altitude, HR: heart rate, FEV1: forced expiratory volume of one sec, FVC: expiratory flow rate obtained by fastest expiration after maximal inhalation, PEF: peak expiratory flow, FEV1/FVC: the ratio of forced expiration volume for $1 \mathrm{sec}$ to forced vital capacity.

lege at high altitude were determined. HR, PEF, and FEV1/ FVC levels of the students living at high altitude were lower while their oxygen saturation, FEV1, and FVC levels were higher than the levels of the students living at low altitude. There were significant differences between the two groups of students in all the measured item $(\mathrm{p}<0.01)$ (Table 1$)$. That is, the HR of students living at high altitude was slower while their oxygen saturation, lung capacity, and inspiratory capacity levels were higher than the levels of students living at low altitude.

Differences in oxygen saturation, bpm, and respiratory function levels of students living at low and high altitudes were determined according to grade. First-year students showed statistically significant differences in all items, except for bpm and FEV, between students living at low and high altitudes $(p<0.01)$. Second-year students showed statistically significant differences in all items, except for oxygen saturation levels, between students living at low and high altitudes $(\mathrm{p}<0.05, \mathrm{p}<0.01)$. Third-year students showed no significant difference in any item. Fourth-year students showed a significant difference only in FVC $(p<0.05)$. HR and PEF levels of students living at high altitude were lower while their oxygen saturation, FEV1, and FVC levels were higher than the levels of students living in a low-altitude place. However, first- and second-year students living at high altitude had lower FEV1/FVC levels than students living at low altitude. Therefore, it can be said that living daily at high altitude affects respiratory function (Table 2).

\section{DISCUSSION}

This study aimed to determine whether living at high altitude place can change pulmonary function by comparing the pulmonary functions of female university students living at high and low altitudes. It is generally accepted that HRs at high altitude are higher while oxygen saturation levels are lower than at low altitude. In contrast, maximum oxygen uptake and endurance levels are lower at high altitude than at low altitude ${ }^{9}$. In this study, students living at high altitude had lower HR and higher oxygen saturation levels than students living at low altitude. The reason for this is that the students living at high altitude had adapted to the high-altitude environment and their HR and oxygen saturation levels were similar to those seen in individuals living in a high-altitude environment. Therefore, their HR levels were lower while their oxygen saturation levels were higher than the levels of students living at low altitude when the measurement was done at low altitude.

Changes in the respiratory system at high altitude are related to lung capacity, diffusion capacity, the perfusion and ventilation relationship, and changes in lung ventilation capacity $^{10)}$. In order to reduce the excessive ventilation of the lungs, indigenous people at high altitude have a larger lung capacity and 21-28\% lower residual capacity than those living at low altitude ${ }^{11)}$. In this study, students living at high altitude had higher FEV1 and FVC and lower PEF levels than those of the students living at low altitude a result, which is consistent with previous studies ${ }^{1,10,11)}$. Therefore, it can be said that living daily at high altitude affects pulmonary function. 
HR and PEF levels of students living at high altitude were lower while oxygen saturation, FEV1, and FVC levels were higher than those of students living at low altitude. First-year students showed statistically significant differences in all items, except for bpm and FEV, between living at low and high altitudes and second-year students showed differences in all items, except for oxygen saturation levels. The main items showing physiological changes at high altitude are cardiac output, HR, and pulmonary artery pressure $^{10)}$. In particular, the first- and second-year students who lacked the ability to adapt to daily living at high altitude, had lower FEV1/FVC levels than those of students living at low altitude.

Third-year students living at high altitude showed no significant differences when compared with students living at low altitude, while fourth-year students showed different FVC levels. These results indicate that the pulmonary function of third- and fourth-year students had adapted to living at high altitude through living there for a long period. Our results also showed that cardiac output increased in those taking a rest while living at low altitude as well as those exercising at an earlier time while living at high altitude. However, cardiac output returned to the value seen at sea level once the subjects had adapted to living at high altitude $^{10)}$. This is explained by the fact that people living at low altitude increase pulmonary perfusion and lung capacity in response to the low atmospheric pressure and low oxygen partial pressure when temporarily living at high altitude ${ }^{11)}$. Also, the amount of ventilation experienced while resting does not recover to the value seen at sea level even if complete adaptation is achieved. When living at high altitude for a certain period of time, the human body acclimatizes by increasing pulmonary perfusion and lung capacity, increasing the oxygen-binding capacity of blood and peripheral tissues, and increasing the amount of red blood cells in order to endure the low atmospheric pressure and low partial pressure of oxygen ${ }^{12}$. Therefore, third- and fourth-year students had increased lung capacity and pulmonary perfusion because of adaptation to daily living at high altitude.

Our results suggest that, if an individual is not accustomed to high altitudes of between $1,500 \mathrm{~m}$ or $3,000 \mathrm{~m}$ above sea level, living at high altitude would mainly elicit physiological changes in oxygen saturation and pulmonary function. However, this study did not identify how long a daily living period at high altitude is needed to influence pulmonary function enough that it can improve the perfor- mance of athletes. In addition, the students living at high altitude did not stay at high altitude all the year round, only for 30 weeks of the year. Thus, the time spent at school at high altitude would be much shorter than 30 weeks. Nonetheless, our study results show that there were changes in oxygen saturation and pulmonary function levels, even under such conditions. Therefore, it would be a good idea to search for measures to utilize high-altitude locations to improve the pulmonary function of athletes. That is, changes in pulmonary function can be obtained through training that alternates between low- and high-altitude locations. It would be more advantageous to open a training field at high altitude and have athletes stay there for a certain period rather than travel overseas to training facilities at a high altitude locations, in terms of finances and the administration of athletes. Thus, an in-depth study should be conducted of pulmonary function and physiological changes at high altitude. Also, future research of male subjects and individuals of various ages is needed.

\section{REFERENCES}

1) Ward MP, Milledges JS, Ward MP, et al.: High Altitude Medicine and Physiology. Philadelphia: University of Pennsylvania Press. 1989, pp 349_ 352 .

2) Joung DS: New trend of high altitude training. Sports Science, 2002, 81: $44-51$

3) Daniels J, Oldridge N: The effects of alternate exposure to altitude and sea level on world-class middle-distance runners. Med Sci Sports, 1970, 2: 107-112. [Medline]

4) Kim KJ, Kim SH, Byon JY, et al.: Changes of cardiopulmonary function, blood cell parameters, erythropoietin, and cytokines after successive altitude training in marathoners. Exerc Sci, 2011, 20: 119-130.

5) Hahn AG, Gore CJ, Martin DT, et al.: An evaluation of the concept of living at moderate altitude and training at sea level. Comp Biochem Physiol A Mol Integr Physiol, 2001, 128: 777-789. [Medline] [CrossRef]

6) Park DH: Effects of a 3-week Training at the Taebaek Training Center on Levels of Hct and Hb, Running Economy, and 3-km Running Record in Elite Boxing players. Korean J Sports Sci, 2007, 18: 74-83.

7) Roh HL: Changes in respiratory function following intermittent living in the upland environment and the low land environment. J Phys Ther Sci, 2014, 26: 335-339. [Medline] [CrossRef]

8) http://www.ers-education.org/guidelines.aspx.

9) Kim GJ, Jin JO, Lim SG: Aerobic capacities of elite female marathoners after three weeks of training at $1896 \mathrm{~m}$ altitude. Kore J Spor Medi, 1994, 12: 327-343.

10) Lenfant C, Sullivan K: Adaptation to high altitude. N Engl J Med, 1971, 284: 1298-1309. [Medline] [CrossRef]

11) Burri PH, Weibel ER: Influence of changes in environmental oxygen tension on lung structure. Maandschr Kindergeneeskd, 1971, 39: 134-136. [Medline]

12) Kim CK, Ko SK: Adaptation and performance at high altitude. J Spo Scien Rese, 1992, 11: 43-69. 